\title{
Treating gonococcal infections resistant to penicillin in Bangkok: comparison of cefuroxime and spectinomycin
}

\author{
ANUPONG CHITWARAKORN,* CHARAS ARIYARIT,* \\ KANCHANA PANIKABUTRA, * ANUKUL BUATEING,* JAMES BIDDLE, $\uparrow$ \\ SUMNER THOMPSON, $\neq$ AND STUART BROWN† \\ From the *Venereal Disease Division, Ministry of Public Health, Bangkok, Thailand, the + Division of \\ Sexually Transmitted Diseases and STD Laboratory Program, Centers for Disease Control, Atlanta, and \\ the $¥$ Department of Medicine, Emory University Medical School, Atlanta, Georgia, USA
}

SUMMARY Gonococcal organisms have become resistant to antimicrobials throughout the world. Such resistance is common in Thailand, where $40 \%$ of gonococci produce penicillinase (PPNG strains) and over half the remainder have MICs of penicillin $\geq 1 \mathrm{mg} / \mathrm{l}$. To evaluate the effectiveness of cefuroxime against such resistant organisms, a controlled clinical trial comparing spectinomycin and cefuroxime was conducted at Bangrak Hospital, Bangkok, in 1982-3. Of 472 patients who were randomly assigned to treatment, $365(77 \%)$ yielded positive cultures before treatment and returned for follow up evaluation three to 13 days after treatment. Of the 365 patients, $359(98 \%)$ were cured, and no difference between the two treatment regimens was found either by the sex of the patient or by the presence of PPNG strains. The MIC of cefuroxime against all organisms was $\leq 1 \mathrm{mg} / \mathrm{l}$. In vitro susceptibilities of gonococci in Bangkok have not changed appreciably during the past two years. Regimens of cefuroxime and spectinomycin are highly effective even for the relatively resistant gonococci in Bangkok. The pharmacokinetics, in vitro susceptibilities, and effectiveness of cefuroxime encourage evaluation of lower doses of the drug.

\section{Introduction}

Plasmid mediated production of penicillinase by strains of Neisseria gonorrhoeae (PPNG strains) has become common throughout the world; chromosomally mediated resistance to penicillin is also increasing. ${ }^{1}$ A survey in Bangkok in 1978 showed that PPNG strains caused $8.6 \%$ of all gonococcal infections. ${ }^{2}$ Recently PPNG strains caused more than $40 \%$ of gonococcal infections in Bangkok ${ }^{3}$ and more than $10 \%$ in other Thai cities (Thai Venereal Disease Division, quarterly reports $1980-3$, unpublished). MICs of penicillin $\geq 1 \mathrm{mg} / \mathrm{l}$ were also found against more than half the non-PPNG strains in Bangkok. ${ }^{3}$

Although gonococci resistant to penicillin are much less common in the United States, where

Address for reprints: Dr A Chitwarakorn, Bangrak Hospital, VD Control Division, 189 South Sathorn Road, Bangkok 10120,

Accepted for publication 14 January 1985
PPNG strains account for less than $0.5 \%$ of all gonococcal infections, a prevalence of more than $5 \%$ has been noted in three major metropolitan areas. ${ }^{4}$ Gonococci that are chromosomally resistant to penicillin have been identified in several outbreaks in the United States. 56

A single $2 \mathrm{~g}$ dose of spectinomycin has been proved to be a safe and effective treatment of infections with gonococci that are resistant or susceptible to penicillin. Gonococci resistant to both penicillin and spectinomycin, however, have recently been identified in sporadic cases in several countries and in a small epidemic. ${ }^{7}$ The gonococcus continues to exhibit the ability to develop resistance to antimicrobials, which necessitates the evaluation of new therapeutic agents to treat gonorrhoea.

Cefuroxime appears to be safe and effective in treating uncomplicated gonococcal infections. ${ }^{8-12}$ Studies of serum cefuroxime concentrations, susceptibilities of gonococci in vitro, and limited clinical observations suggest that this drug would be 
an effective agent for treating gonococcal infections that are resistant to penicillin. ${ }^{13-16}$

\section{Patients and methods}

SELECTION AND MANAGEMENT OF PATIENTS The routine procedures used to examine patients attending the sexually transmitted disease (STD) clinics of Bangrak Hospital, Bangkok have been described previously. ${ }^{17}$ These procedures included screening for gonococcal infection using Gram stained smears of material from the urethra of men and from the urethra, endocervix, and rectum of women. Material for culture of $N$ gonorrhoeae was also obtained from these sites in women. If gonococci were not identified from a smear, patients were asked to return when culture results were available.

We considered patients to be eligible for this study if a smear contained intracellular Gram negative diplococci at the initial visit or if $N$ gonorrhoeae was isolated on culture. Patients who were pregnant, allergic to the drugs being studied, aged under 18 , or suffering from syphilis, chancroid, or complications of gonococcal infections were excluded from participation. We examined and recorded the histories of all participants, who were then randomly assigned to receive either cefuroxime $1.5 \mathrm{~g}$ reconstituted with sterile water intramuscularly and probenecid $1 \mathrm{~g}$ by mouth or spectinomycin $2 \mathrm{~g}$ reconstituted with sterile water intramuscularly. Patients were asked to abstain from sexual intercourse before the follow up visit one week later.

At the return visit we re-examined patients, confirmed their histories, and took further material for culture of $N$ gonorrhoeae from the same anatomical sites as at the first visit. Side effects were identified by asking each patient whether they had experienced pain at the injection site, diarrhoea, nausea, vomiting, rash, itching, or other problems. Injection pain was considered to be important only if the pain lasted several hours.

\section{LABORATORY METHODS}

All specimens were immediately inoculated on to modified Thayer-Martin medium, placed in candle extinction jars, and incubated at $35-36^{\circ} \mathrm{C}$ within one hour. Typical Gram negative diplococci in oxidase reactive colonies growing on selective medium were presumptively identified as $N$ gonorrhoeae. The identity of these isolates was confirmed using the rapid sugar utilisation technique. ${ }^{18}$ Isolates were tested for penicillinase production using the starch paper method. ${ }^{19}$

Gonococcal isolates were suspended in trypticase soy broth with glycerol and stored at $-70^{\circ} \mathrm{C}$. Frozen isolates were shipped to the Centers for Disease Control (CDC), Atlanta, Georgia, USA, where their identities were reconfirmed. ${ }^{3}$ Agar plate dilution tests were used to measure the minimum inhibitory concentrations (MICs) of 11 antibiotics against each isolate. The ranges of concentrations of antimicrobials tested were: penicillin G 0.004 to $64 \mathrm{mg} / \mathrm{l}$, cefuroxime 0.015 to $2 \mathrm{mg} / 1$, cefoxitin 0.06 to $8 \mathrm{mg} / 1$, cefotaxime 0.002 to $0.5 \mathrm{mg} / \mathrm{l}$, tetracycline 0.06 to $8 \mathrm{mg} / \mathrm{l}$, erythromycin 0.015 to $2 \mathrm{mg} / \mathrm{l}$, spectinomycin 2 to $256 \mathrm{mg} / \mathrm{l}$, kanamycin $0 \cdot 125$ to $64 \mathrm{mg} / \mathrm{l}$, thiamphenicol 0.125 to $8 \mathrm{mg} / \mathrm{l}$, and trimethoprim-sulphamethoxazole 0.03 and 0.6 to 2 and $38 \mathrm{mg} / \mathrm{l}$.

\section{ANALYSIS OF DATA}

Only patients with a positive culture for $N$ gonorrhoeae on the day of treatment and who returned for re-evaluation three to 13 days after treatment were included in the analysis of results. All patients yielding $N$ gonorrhoeae at follow up were considered to have failed treatment.

STATISTICAL ANALYSIS

We used Student's $t$ test and the $\chi^{2}$ test.

\section{Results}

From August 1982 to May 1983 we studied 472 men and women attending the Bangrak STD clinic with presumptive gonococcal infections. After obtaining informed written consent we treated 236 with spectinomycin and 236 with cefuroxime. The cultures obtained at the time of entry into the study were negative in 35 patients, and 72 other patients failed to return for follow up evaluation three to 13 days after treatment. Thus the final study population consisted of 365 patients who yielded positive cultures before treatment and returned for follow up.

The age, marital status, occupation, reasons for attending the clinic, recent sexual history, and examination findings of patients were similar in the two treatment groups but were different for men and women. Table I shows that $98 \%$ of the patients were cured, and cure rates did not vary according to the drug used for treatment, sex of the patient, or penicillinase test results.

More than $90 \%(329 / 365)$ of the patients were asymptomatic at follow up. Although dysuria or discharge, or both, were more common in men treated with cefuroxime $(12 \%(22 / 181))$ than with spectinomycin $(6 \%(11 / 184))$, these differences were not significant by $\chi^{2}$ analysis. Only 14 patients $(4 \%)$ gave a history of sexual intercourse between treatment and re-evaluation; three of these 14 patients were not cured. 
Of the 181 patients treated with cefuroxime, 53 (29\%) noted appreciable pain at the injection site, although in none did this pain interfere with normal activities. Injection site pain was appreciably more common among patients receiving cefuroxime than in those who received spectinomycin. No other side effect was common or appreciably more common in one treatment group than the other.

We measured the in vitro susceptibilities to 11 antimicrobials of isolates taken before treatment from 357 patients, 144 (40\%) of which were PPNG strains. Tables II and III show that out of the 213 non-PPNG strains tested, MICs of penicillin $\geq 1 \mathrm{mg} / \mathrm{l}$ were found in $72(34 \%)$. Out of all 357 isolates, MICs of tetra-

TABLE I Results of treating 365 uncomplicated gonococcal infections with spectinomycin $2 \mathrm{~g}$ or cefuroxime $1.5 \mathrm{~g}$ plus probenecid $1 \mathrm{~g}$ in Bangkok, 1982-3

\begin{tabular}{lllll}
\hline Treatment & Strains & $\begin{array}{l}\text { No of } \\
\text { patients }\end{array}$ & $\begin{array}{l}\text { No of } \\
\text { treatment } \\
\text { failures }\end{array}$ & $\begin{array}{l}\text { No (\%) } \\
\text { cured }\end{array}$ \\
\hline $\begin{array}{l}\text { Spectinomycin: } \\
\text { Men }\end{array}$ & PPNG & 41 & 1 & $40(98)$ \\
Women & Non-PPNG & 67 & 0 & $67(100)$ \\
& PPNG & 28 & 0 & $28(100)$ \\
Total & Non-PPNG & 48 & 2 & $46(96)$ \\
& PPNG & 69 & 1 & $68(99)$ \\
& Non-PPNG 115 & 2 & $113(98)$ \\
Cefuroxime: & & & & \\
Men & PPNG & 37 & 0 & $37(100)$ \\
Women & Non-PPNG & 64 & 1 & $63(98)$ \\
& PPNG & 38 & 1 & $37(97)$ \\
Totalt $t$ & Non-PPNG & 41 & 1 & $40(98)$ \\
& PPNG & 75 & 1 & 74 \\
& Non-PPNG 105 & 2 & $103(99)$ \\
\hline
\end{tabular}

PPNG = penicillinase producing Neisseria gonorrhoeae.

*Patients with positive cultures before treatment who attended follow up after three to 13 days.

$\dagger \beta$ lactamase test not performed on one additional patient, who was cured but is not included in table. cycline $\geq 2 \mathrm{mg} / 1$ occurred in $289(81 \%)$ MICs of erythromycin $\geq 0.25 \mathrm{mg} / \mathrm{l}$ in $327(92 \%)$ and MICs of trimethoprim-sulphamethoxazole $\geq 0.5$ and $9.5 \mathrm{mg} / 1$ in $244(71 \%)$. No resistance to spectinomycin was identified, but $104(29 \%)$ isolates had an MIC of kanamycin $\geq 32 \mathrm{mg} / \mathrm{l}$. Small but significant differences were found between the distribution of MICs of tetracycline, erythromycin, spectinomycin, kanamycin, and thiamphenicol for PPNG and nonPPNG organisms (table III).

We sought to identify the recent use of antibiotics in this population, but found that we could generally only categorise medications by whether they had been intended to treat infections, not whether they were actually antibiotics. Appreciably more men $(69 / 210(33 \%))$ than women $(34 / 155(22 \%))$ had used antimicrobial agents in the preceding two weeks $\left(\alpha^{2}=4.7 ; p<0.05\right)$. Of the 144 patients infected with PPNG strains, $49(34 \%)$ admitted recent use of medications. Of the 209 infected with non-PPNG strains whose histories we had obtained, $55(26 \%)$ admitted using medication recently. This difference was not significant $\left(\chi^{2}=2 \cdot 2 ; p>0 \cdot 05\right)$. Among the 209 patients infected with non-PPNG strains, MICs of penicillin were higher among those who had recently used medication, although this difference was not significant (table IV).

\section{Discussion}

We found that $1.5 \mathrm{~g}$ cefuroxime plus $1 \mathrm{~g}$ probenecid was a highly effective treatment of uncomplicated penicillin resistant and non-resistant gonococcal infections in Bangkok. Cefuroxime MIC distributions were not significantly different for PPNG and non-PPNG strains. The therapeutic effectiveness of cefuroxime could have been predicted on the basis of these MICs.

TABLE II Distribution of susceptibilities to $\beta$ lactam antimicrobials of penicillinase producing Neisseria gonorrhoeae (PPNG) and non-PPNG strains isolated in Bangkok, 1982-3

\begin{tabular}{|c|c|c|c|c|c|c|c|c|c|c|c|c|c|}
\hline \multirow[b]{2}{*}{ Agent } & \multicolumn{13}{|c|}{ No of strains with minimum inhibitory concentrations $(\mathrm{mg} / \mathrm{l})$ of: } \\
\hline & 0.002 & 0.004 & 0.008 & 0.015 & 0.03 & 0.06 & $0 \cdot 125$ & $0 \cdot 25$ & 0.5 & 1 & 2 & 4 & 8 \\
\hline \multicolumn{14}{|l|}{ Penicillin G } \\
\hline PPNG & & & & & & & & & & 2 & 6 & 26 & 110 \\
\hline $\begin{array}{l}\text { Non-PPNG } \\
\text { Cefuroxime* }\end{array}$ & & & & & 2 & 12 & 28 & 45 & 54 & 51 & 18 & 3 & \\
\hline PPNG & & & & 12 & 23 & 30 & 44 & 22 & 11 & 2 & & & \\
\hline $\begin{array}{c}\text { Non-PPNG } \\
\text { Cefoxitin }\end{array}$ & & & 1 & 32 & 36 & 63 & 37 & 13 & & & & & \\
\hline PPNG & & & & & & & & 7 & 31 & 69 & 37 & & \\
\hline $\begin{array}{c}\text { Non-PPNG } \\
\text { Cefotaxime* }\end{array}$ & & & & & & & & 8 & 41 & 88 & 74 & 2 & \\
\hline $\begin{array}{l}\text { PPNG } \\
\text { Non-PPNG }\end{array}$ & $\begin{array}{l}25 \\
41\end{array}$ & $\begin{array}{l}37 \\
50\end{array}$ & $\begin{array}{l}38 \\
43\end{array}$ & $\begin{array}{l}38 \\
64\end{array}$ & $\begin{array}{r}6 \\
14\end{array}$ & 1 & & & & & & & \\
\hline
\end{tabular}

PPNG = penicillinase producing Neisseria gonorrhoeae.

*Differences between distributions of PPNG and non-PPNG strains not significant $\left(x^{2} ; p>0 \cdot 05\right)$. 
TABLE III Distribution of susceptibilities to non-B-lactam antimicrobials of penicillinase producing Neisseria gonorrhoeae . (PPNG) and non-PPNG strains isolated in Bangkok, 1982-3

\begin{tabular}{|c|c|c|c|c|c|c|c|c|c|c|c|c|c|c|}
\hline \multirow[b]{2}{*}{ Agent } & \multicolumn{14}{|c|}{ No of strains with minimum inhibitory concentrations $(\mathrm{mg} / \mathrm{l})$ of: } \\
\hline & 0.015 & 0.03 & 0.06 & $0 \cdot 125$ & 0.25 & 0.5 & 1 & 2 & 4 & 8 & 12 & 16 & 32 & 64 \\
\hline Tetracycline* & & & & & & & & & & & & & & \\
\hline PPNG & & & & & & 7 & 17 & 47 & 69 & 4 & & & & \\
\hline Non-PPNG & & & & & 1 & 24 & 19 & 85 & 84 & & & & & \\
\hline Erythromycin* & & & & & & & & & & & & & & \\
\hline PPNG & 1 & & 2 & 1 & 4 & 43 & 79 & 14 & & & & & & \\
\hline $\begin{array}{l}\text { Non-PPNG } \\
\text { Spectinomycin }\end{array}$ & 3 & 13 & 5 & 5 & 6 & 37 & 118 & 26 & & & & & & \\
\hline $\begin{array}{l}\text { Spectinomycin* } \\
\text { PPNG }\end{array}$ & & & & & & & & & & 41 & 77 & 25 & 1 & \\
\hline Non-PPNG & & & & & & & & & & $\begin{array}{l}41 \\
79\end{array}$ & 89 & 36 & 9 & \\
\hline Kanamycin* & & & & & & & & & & & & & & \\
\hline PPNG & & & & & & & & & 5 & 13 & & 74 & 45 & 7 \\
\hline Non-PPNG & & & & & & & 1 & 1 & & 38 & & 121 & 41 & 11 \\
\hline Thiamphenicol* & & & & & & & & & & & & & & \\
\hline PPNG & & & & & & 1 & 39 & 102 & 2 & & & & & \\
\hline Non-PPNG & & & & & 2 & 2 & 96 & 110 & 2 & 1 & & & & \\
\hline Trimethoprim $†$ & & & & & & & & & & & & & & \\
\hline $\begin{array}{l}\text { PPNG } \\
\text { Non-PPNG }\end{array}$ & & $\begin{array}{l}1 \\
8\end{array}$ & $\begin{array}{l}2 \\
2\end{array}$ & 8 & $\begin{array}{l}34 \\
43\end{array}$ & $\begin{array}{l}58 \\
91\end{array}$ & $\begin{array}{l}36 \\
44\end{array}$ & $\begin{array}{r}4 \\
11\end{array}$ & & & & & & \\
\hline
\end{tabular}

PPNG = penicillinase producing Neisseria gonorrhoeae.

*Differences between PPNG and non-PPNG strains significant ( $\mathrm{p}<0 \cdot 05) ; \chi^{2}=8.9$ (tetracycline), $16 \cdot 5$ (erythromycin), $8 \cdot 3$ (spectinomycin), 13.1 (kanamycin), and 12.6 (thiamphenicol).

tTrimethoprim and sulphamethoxazole in a ratio of $1: 19$.

The pharmacokinetics of, and in vitro susceptibility of gonococci to, cefuroxime and the efficacy of the regimen suggest that doses of cefuroxime lower than we used would also cure more than $95 \%$ of infections. Serum cefuroxime concentrations were

TABLE IV Susceptibility to penicillin of 209 strains of nonpenicillinase producing Neisseria gonorrhoeae according to history of recent use of medication, Bangkok, 1982-3

\begin{tabular}{llrllllllll}
\hline $\begin{array}{l}\text { Medication } \\
\text { in previous } \\
14 \text { days }\end{array}$ & \multicolumn{6}{l}{ No of strains with MICs $(\mathrm{mg} / \mathrm{l})$ of: } & \\
\cline { 2 - 7 } & $<0.03$ & 0.06 & 0.125 & 0.25 & 0.5 & 1 & 2 & 4 & Total \\
\hline Used & 1 & 3 & 7 & 8 & 15 & 16 & 4 & 1 & 55 \\
Not used & 1 & 9 & 21 & 34 & 38 & 35 & 14 & 2 & 154 \\
Total & 2 & 12 & 28 & 42 & 53 & 51 & 18 & 3 & 209 \\
\hline
\end{tabular}

MIC = minimum inhibitory concentration.

highest one hour after an intramuscular injection, when a mean (SD) of $40(8 \cdot 9) \mathrm{mg} / \mathrm{l}$ was achieved after $1 \mathrm{~g} \mathrm{had}$ been given. ${ }^{20}$ Probenecid greatly prolonged the serum cefuroxime half life from $1 \frac{1}{2}$ hours. We found MICs of cefuroxime $\leq 1.0 \mathrm{mg} / 1$ against all gonococci. Thus cefuroxime $1.5 \mathrm{~g}$ plus probenecid $1 \mathrm{~g}$ produced serum concentrations more than 10 times the highest MIC for several hours, a concentration far exceeding what is needed to cure gonococcal infections. ${ }^{21}$ As . Thai patients treated with $0.75 \mathrm{~g}$ or $1.5 \mathrm{~g}$ cefuroxime plus $1 \mathrm{~g}$ probenecid had serum cefuroxime concentrations of $24 \mathrm{mg} / 1$ and $35 \mathrm{mg} / \mathrm{l}$, respectively, ${ }^{16}$ a lower dose of cefuroxime may be effective even in Bangkok where gonococci are clinically refractory to many antimicrobials.

Previous investigations at the Bangrak STD clinic showed that less than $2 \%$ of pharyngeal cultures from men or women with gonorrhoea yielded $N$ gonorrhoeae. We therefore did not study gonococcal infection at that anatomical site. In circumstances in which pharyngeal infections are more common, however, drug efficacy for pharyngeal infection might be important when selecting a standard treatment regimen. As cephalosporins and spectinomycin are ineffective single dose regimens for pharyngeal gonococcal infections, other agents might be preferred.22

Chlamydia trachomatis has often been identified in men at the Bangrak STD clinic who have nongonococcal urethritis (NGU) (Suvongse C, unpublished observation). Postgonococcal urethritis (PGU) develops in about $40 \%$ of men treated for gonorrhoea at this clinic, which probably reflects coincidental infections with gonococci and chlamydiae. ${ }^{23}$. We anticipate that PGU will be common after treatment with cefuroxime, as single dose regimens of cephalosporins will cure few chlamydial infections. ${ }^{24}$ It may become necessary to consider treating patients who have gonorrhoea with a seven day course of tetracycline to eradicate chlamydial infections.

Injection pain was the only major side effect of cefuroxime noted in this study, but it was not disabling in any patient. Pain at the injection site is a problem generally encountered with the cephalosporins. ${ }^{11}$ Reconstitution with $0.5 \%$ lignocaine has 
reduced injection pain associated with other cephalosporins and may be useful for cefuroxime.

The high cure rates observed in this study deserve note. We believe that these were due to highly effective antibiotics and excellent patient compliance. Nearly $85 \%$ of the patients enrolled in the study returned for follow up examination within two weeks, and only $5 \%$ of these patients had had sexual re-exposure before the follow up visit. Many therapeutic studies have much lower follow up rates with higher re-exposure rates, both of which factors artificially reduce the reported cure rates.

Both kanamycin and thiamphenicol are used commonly in Thailand and other countries with a high prevalence of PPNG strains. We observed substantial in vitro resistance to these drugs, and failure rates of $5 \%$ for kanamycin and $12 \%$ for thiamphenicol have been seen in the Bangrak clinic. ${ }^{17}$ Several cephalosporin regimens have been highly effective against infections with gonococci resistant to penicillin and have been recommended for regions with a high prevalence of PPNG strains. ${ }^{1}$ The choice between several cephalosporins and spectinomycin is likely to be dictated by cost and availability. Currently in Bangkok, a $1.5 \mathrm{~g}$ dose of cefuroxime costs 320 Baht (US \$14.50), compared with 124 Baht for spectinomycin $2 \mathrm{~g}, 110$ Baht for ceftriaxone $250 \mathrm{mg}, 110$ Baht for cefotaxime $500 \mathrm{mg}$, and 320 Baht for cefoxitin $2 \mathrm{~g}$. As costs and availability are changing rapidly, these 1983 costs in Thailand may not apply generally.

Cefuroxime is an attractive, although expensive, therapeutic agent for gonococcal infections resistant to penicillin. It is a safe, well tolerated, single dose regimen that is highly effective. In addition, cefuroxime is active against experimental infection with syphilis, ${ }^{25}$ so this treatment for gonorrhoea would abort some incubating infections with Treponema pallidum. Patients of ten treat themselves in Thailand, however, which contributes to the selection of gonococcal strains resistant to penicillin: As cefuroxime and other new agents are introduced and become more widely used, it will be important to monitor patterns of susceptibility. Resistance to this and other cephalosporins may develop as the drugs are used more widely.

This work was supported in part by a grant from Glaxo Incorporated. Without the assistance of the nursing staff and technicians of the Bangrak clinic the study would not have been possible. We thank G Holcomb, U Ruayruin, and $\mathbf{P}$ McConnon for their help. The support and encouragement of Dr Amnuay Traisupa were essential for the development and completion of this study.

\section{References}

i. World Health Organisation Consultative Group. Current treatments in the control of sexually transmitted diseases.
Report of a scientific working group. WHO/VDT/83 1983; 433:6-10.

2. Panikabutra $\mathrm{K}$, Suvannamalik S. Penicillinase producing $N$ gonorrhoeae and its therapeutic aspects in Bangkok, Thailand. Journal of the Venereological Group of Thailand 1981; 7: 22-38.

3. Brown ST, Warnnissorn T, Biddle J, Panikabutra K, Traisupa A. Antimicrobial resistance of Neisseria gonorrhoeae in Bangkok: is single-drug treatment passé? Lancet 1982; ii: 1366-8.

4. Jaffe HW, Biddle JW, Johnson SR, Wiesner PJ. Infections due to penicillinase-producing Neisseria gonorrhoeae in the United States 1976-1980. J Infect Dis 1981; 144:191-7.

5. Centers for Disease Control. Penicillin-resistant gonorrhoea-North Carolina. MMWR 1983;32:273-5.

6. Centers for Disease Control. Chromosomally resistant Neisseria gonorrhoeae in the United States, 1983-1984. MMWR 1984; 33:408-10.

7. Centers for Disease Control. Spectinomycin-resistant penicillinase-producing Neisseria gonorrhoeae. MMWR 1983; 32:51-2.

8. Fowler W, Rahim G, Brown JD. Clinical experience in the use of cefuroxime in gonorrhoea. British Journal of Venereal Diseases 1978;54:400-2.

9. Price JD, Fulker JL. The efficacy of cefuroxime for the treatment of acute gonorrhoea in men. British Journal of Venereal Diseases 1978;54: 165-72.

10. Morrison GD, Evans AJ, Hosking HW, et al. Cefuroxime compared with penicillin for the treatment of gonorrhoea. Sex Transm Dis 1980; 7: 188-90.

11. Lossick JG, Thompson SE, Smeltzer MP. Comparison of cefuroxime and penicillin in the treatment of uncomplicated gonorrhoea. Antimicrob Agents Chemother 1982; 22:409-13.

12. Patamasucon $P$, Rettig PJ, Nelson JD. Cefuroxime therapy of gonorrhoea and coinfection with Chlamydia trachomatis in children. Pediatrics 1981;68:534-8.

13. Nayyar KC, Michel MF, Stolz E. Antibiotic sensitivities of gonococci isolated in Rotterdam and results of treatment with cefuroxime. British Journal of Venereal Diseases 1980; 56:249-51.

14. Arya OP, Rees E, Percivial A, Alergant CD, Annels EH, Turner GC. Epidemiology and treatment of gonorrhoea caused by penicillinase-producing strains in Liverpool. British Journal of Venereal Diseases 1978;54:28-35.

15. Tupasi TE, Crisologo LB, Torres CA, Calubiran OV Comparison of spectinomycin, cefuroxime, thiamphenicol and penicillin $G$ in the treatment of uncomplicated gonococcal infections in women. J Infect Dis 1982; 145:583.

16. Polnikorn N, Vorachit M, Pauvilai S, Charuvichitratana $S$. The penicillinase producing Neisseria gonorrhoeae and treatment with cefuroxime. Ramathibodi Medical Journal 1981; 4:234-8.

17. Panikabutra K, Ariyarit C, Chitwarakorn A, Warnnissorn T, Saensanoh C. Sensitivity to penicillin, thiamphenicol, kanamycin, cefoxitin and spectinomycin of penicillinaseproducing Neisseria gonorrhoeae (PPNG) in Bangkok. J Med Assoc Thai 1982;65;316-24.

18. Kellogg DS Jr, Turner EM. Rapid fermentation confirmation of Neisseria gonorrhoeae. Applied Microbiology 1973; 25:550-2.

19. World Health Organisation. Neisseria gonorrhoeae and gonococcal infections. WHO Tech Rep Ser 1978;616:138-9.

20. Foord RD. Cefuroxime: human pharmacokinetics. Antimicrob Agents Chemother 1976;9:741-7.

21. Jaffe HW, Schroeter AL, Reynolds GH, Zaid AA, Martin JE Jr. Thayer JD. Pharmacokinetic determinants of penicillin cure of gonococcal urethritis. Antimicrob Agents Chemother 1979; 15:587-91.

22. Lindberg $M$, Ringertz $O$, Sandstrom E. Treatment of pharyngeal gonorrhoea due to $\beta$-lactamase-producing gonococci. British Journal of Venereal Diseases 1982;58:101-4.

23. Panikabutra K, Ariyarit C, Chitwarakorn A, Saensanoh C. Rosoxacin in the treatment of uncomplicated gonorrhoea in men. British Journal of Venereal Diseases 1984;60:231-4.

24. Thompson SE, Washington AE, Epidemiology of sexually transmitted Chlamydia trachomatis infections. Epidemiol Rev 1983;5:96-123.

25. Acred P, Grujic P, Ryan DM, Xerri L, Orsolini P, Erani E. In vitro activity of cefuroxime against Treponema pallidum and Neisseria gonorrhoeae. JAntimicrob Chemother 1980; 6:407-8. 